\title{
Micronutrients status among human immunodeficiency virus-infected children in Southern India
}

\author{
Sangeetha Sivasubramanian ${ }^{1}$, Janardhan Shenoy ${ }^{1}$, Sowmini P. Kamath ${ }^{1}$, Vaman Kulkarni ${ }^{2}$, \\ Mukund Srinivasan ${ }^{3}$, Shantharam Baliga $\mathrm{B}^{1}$ \\ ${ }^{1}$ Department of Pediatrics, Kasturba Medical College, Mangalore, Manipal Academy of Higher Education, Manipal, Karnataka, India \\ ${ }^{2}$ Department of Community Medicine, Kasturba Medical College, Mangalore, Manipal Academy of Higher Education, Manipal, \\ Karnataka, India \\ ${ }^{3}$ Department of Pathology, University of Texas, Galveston, Texas
}

\begin{abstract}
Introduction: Deficiencies of micronutrients play a role in human immunodeficiency virus (HIV) infection and its severity. Identifying the micronutrient status would guide supplementation, thus altering the disease progression and severity.

Material and methods: A cross-sectional hospital-based study was conducted in Southern India on hundred HIV-infected children. Estimation of serum micronutrient levels (zinc, copper, and iron) and comparison of the deficient micronutrients with clinical stages, immunological categories, CD4 counts, and nutritional status was performed.

Results: Among 100 HIV-infected children, zinc deficiency was the most common (62\%), whereas copper and iron deficiency was present in $2 \%$ and $1 \%$, respectively. Mean age of children was $11.20 \pm$ 3.14 years, $52 \%$ were girls, $24 \%$ were malnourished, $76 \%$ were receiving antiretroviral therapy (ART), and four had CD4 counts $<200 / \mathrm{mm}^{2}$ indicating AIDS. Using Kruskalwallis test, serum iron levels $(p=0.000)$ and CD4 levels $(p=0.001)$ were significantly associated with clinical stages, while serum zinc levels $(p=0.043)$ and CD4 levels $(p=0.000)$ were significantly associated with various degrees of immune classification. Mean micronutrient levels did not correlate significantly with CD4 counts less than and greater than 350 by unpaired $t$ test. Zinc deficiency did not correlate with clinical staging, immunological classification, nutritional status, and receipt of ART on multiple logistic regression analysis.

Conclusion: In HIV-infected children, zinc deficiency was the most common and it did not correlate with clinical staging, immunological classification, nutritional status, and receipt of antiretroviral therapy. Hence, supplementation of zinc would be required along with initiation of ART.
\end{abstract}

HIV AIDS Rev 2020; 19, 1: 56-60 DOI: https://doi.org/10.5114/hivar.2020.93062

Key words: child, copper, HIV infections, iron, micronutrients, zinc.

Address for correspondence: Dr. Sowmini P. Kamath, Kasturba Medical College, Mangalore, Light house hill road, Hampankatta, Mangalore, 575001, Mangalore, India, e-mail: kamathsowmini@yahoo.com
Article history:

Received: 08.04.2019

Received in revised form: 17.07.2019

Accepted: 09.08.2019

Available online: 30.01 .2020
International Journal of HIV-Related Problems

HIV \& AIDS

$R$ e vi e w 


\section{Introduction}

In the world, India is ranked third for human immunodeficiency virus (HIV)-infected population, with an annual birth of about 30,000 infected infants from an estimated 100,000 infected women [1]. In India, people living with HIV in 2011 were estimated to be 20.88 lakhs, with approximately seven per cent being children less than 15 years of age [2].

Micronutrient deficiencies cause nutritionally acquired immunodeficiency syndrome, which contributes to CD4+ cells depletion, increasing susceptibility to opportunistic infections [3, 4]. HIV progression leads to reduced absorption, increased utilization, and loss of micronutrients. Micronutrient deficiency in turn increases the infectious disease morbidity by affecting host defense, thus forming a vicious cycle $[3,5]$. Therefore, a preventive/therapeutic use of micronutrients may reduce infectious/opportunistic disease morbidity and mortality among HIV children in developing countries [5].

Zinc is essential for DNA synthesis, cell growth, mucosal epithelization, wound healing [6], and immune response regulation [7]. Decreased zinc levels leads to susceptible oxidative stress and impairment of cell function $[8,9]$. Zinc is an integral part of catalytic and structural proteins of HIV, and it inhibits HIV replication by binding to the catalytic site of HIV protease [10, 11].

Copper modulates MHC class 2 expression and possess antioxidant activity. Iron contributes to free radical generation, DNA replication, protein synthesis, cell proliferation, and has a role in cellular metabolism [12].

Until recently, very few studies have been globally conducted on micronutrients status of HIV-infected children [13-15], with a single study from India [16]. The results obtained from these studies still remain inconclusive, as they are considerably limited by small number of study participants. Here, we evaluated the micronutrient status of zinc, copper, and iron among HIV-infected children between the age group of two to 15 years, and compared their levels with clinical staging, immunological categories, nutritional status, CD4 count, and antiretroviral treatment for any significant correlation.

\section{Material and methods}

This cross-sectional study was conducted from November 2013 till November 2014 at tertiary care referral hospitals in Southern India. Children with HIV, aged between two to 15 years, who visited antiretroviral therapy (ART) center were included. Sample size was calculated at 106 based on prevalence of zinc deficiency as $54.3 \%$ [13], with $80 \%$ power, $95 \%$ confidence level, and $10 \%$ non-response rate. After obtaining an approval from the Institutional Ethics Committee (IEC) and the Karnataka State AIDS Prevention Society (KSAPS), necessary permissions were taken from the hospital authorities. Hospitals were visited for data collection. The study subjects were selected using sequential (non-random) sampling technique. HIV children, who either had received supplements within a month prior to study or were presently on supplements, had presence of acute illness (acute febrile illness, acute diarrhea, respiratory tract infections), and who were not willing to give consent were excluded from the study.

For the selected study participants, their parents/guardians were approached and explained about the objectives of the study in a language they understood, with a participant information letter provided. A written informed consent was obtained from each of the parent/guardian. Data collection was done using a semi-structured pretested proforma, which included details about demographic factors and medical history. Weight, length/height were measured using standard techniques. World Health Organization (WHO) growth charts [17] and Khadilkar growth charts [18] were used to assess nutritional status of children less than and greater than five years, respectively. Body mass index was calculated. Clinical staging and immunological staging of HIV was based on WHO staging for children and adolescents [19].

Micronutrients (zinc, copper, and iron) levels were estimated on $3 \mathrm{ml}$ of non-fasting morning venous sample after separation of serum by centrifugation. The kits used were from coral diagnostics (Tulip, Goa). The following assessment techniques were used for estimation of micronutrients levels in blood: nitro-PAPS endpoint method, quantitative colorimetric copper determination at $354 \mathrm{~nm}$, and iron colorimetric assay using ferrozyme for zinc, copper, and iron estimation, respectively. The micronutrient levels (zinc, copper, and iron) below the lower limit of normal range for that specific age was considered as deficiency [20]. Data were analyzed using Statistical Package for Social Sciences (SPSS) version 16 software. Results were presented as mean \pm SD, and median and interquartile range. Kolmogorov-Smirnov test evaluated the normality assumption for continuous variables. One way ANOVA and Kruskal-Wallis tests were adopted for statistical analysis. Linear regression analysis was subsequently performed to identify predictors of micronutrient status among clinical stage, immunological stages, nutrition status, and ART, while controlling for gender and age. A $p$ value $<0.05$ was considered as statistically significant.

\section{Results}

Clinicodemographic characteristics of the study population have been depicted in Table 1. The mean age of HIV-infected children in the study was $11.20 \pm 3.14$ years. The mean serum zinc, copper, and iron levels $(\mu \mathrm{g} / \mathrm{dl})$ were $70.47 \pm 65.42$, $191.57 \pm 106.26$, and $195.39 \pm 94.56$, respectively. The mean serum CD4 counts were $762.45 \pm 375.42$.

Micronutrient status of the study participants is shown in Figure 1, with zinc deficiency being the most common (62\%). Zinc deficiency affected $56.45 \%$ of females in the study. HIV clinical stage 1, 2, and 3 diseases had documented zinc deficiency status in $54.83 \%, 33.87 \%$, and $11.27 \%$, respectively. The 'none', mild, advanced, and severe degrees of HIV immunological classification had zinc deficiency status in $70.97 \%$, $12.90 \%, 8.06 \%$, and $8.06 \%$, respectively. This indicates that early clinical stages and the 'none' group of immunological classification had larger number of zinc deficiency status. Using Kruskal-Wallis test, serum zinc levels, and CD4 levels 
Table 1. Demographic, clinical, immunological, and nutritional status data among human immunodeficiency virus infected children $(n=100)$

\begin{tabular}{l|c}
\hline \multicolumn{1}{l|}{ Variable } & HIV-infected, $n$ \\
\hline \begin{tabular}{l} 
Age, years \\
\hline$<5$
\end{tabular} & 3 \\
\hline $5-10$ & 36 \\
\hline $11-15$ & 61 \\
\hline Gender & 48 \\
\hline Males & 52 \\
\hline Females & \\
\hline Clinical staging & 54 \\
\hline Stage 1 & 34 \\
\hline Stage 2 & 12 \\
\hline Stage 3 & 0 \\
\hline Stage 4 & \\
\hline Immunological classification & 74 \\
\hline None & 14 \\
\hline Mild & 7 \\
\hline Advanced & 5 \\
\hline Severe & 24 \\
\hline Nutritional status & \\
\hline Normal & \\
\hline Underweight & \\
\hline Antiretroviral treatment & \\
\hline Yes & \\
\hline No & \\
\hline
\end{tabular}

were significantly associated with various degrees of immune classification (Table 2). Serum iron levels and CD4 levels were significantly associated with clinical stages (Table 2). Using Student's t test, CD4 levels were significantly associated with nutritional status (0.015); however, there was no association between serum micronutrients and CD4 levels.

Seventy-six HIV-infected children were on ART. HIV clinical stage 1,2, and 3 diseases had receipt of ART in 52.63\%, $34.21 \%$, and $13.16 \%$, respectively. The 'none', mild, advanced, and severe degrees of HIV immunological classification had receipt of ART in $76.32 \%, 10.53 \%, 7.89 \%$, and $5.26 \%$, respectively.

CD4 count $\geq 350$ was present in $96.3 \%$ (52/54), $91.2 \%$ $(31 / 34)$, and $41.7 \%$ (5/12) of HIV clinical stages 1,2 , and 3 , respectively. Three fourths $(18 / 24,75 \%)$ of underweight children and $92.11 \%(70 / 76)$ with normal nutritional status had CD4 count $\geq 350$. The mean micronutrient levels were found to be low in those with CD4 count less than 350, when compared with CD4 count greater than 350 . However, by unpaired t test, $\mathrm{p}$ value was not significant. Zinc deficiency did not correlate with clinical staging, immunological classification, and nutritional status by multiple logistic regression analysis (Table 3 ).

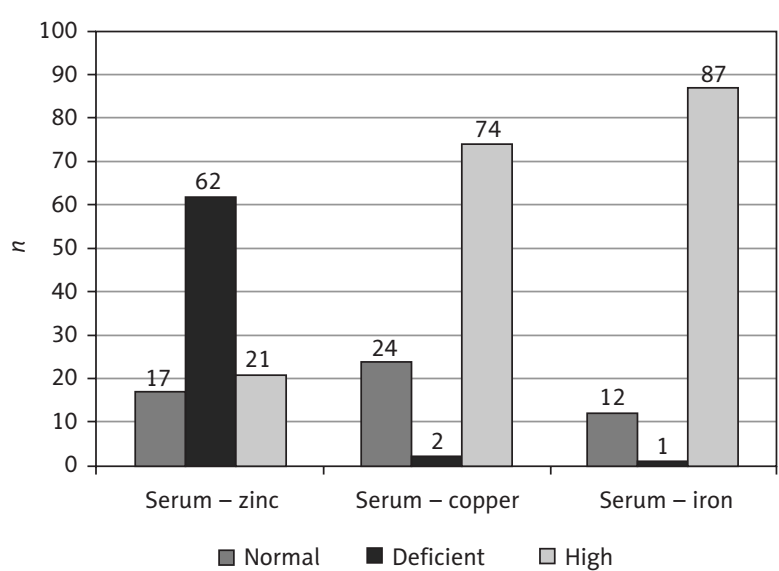

Figure 1. Micronutrient status levels in percentages $(N=100)$

\section{Discussion}

HIV infection and malnutrition form a vicious cycle, with many reports on the influence of micronutrient deficiency on viral load $[21,22]$, progression, and infectivity [22, 23]. Therefore, maintaining normal micronutrients levels is important in HIV infection. In India, children under 15 years with HIV have increased from 1.42 lakhs (2007) to 1.45 lakhs (2011), with a growth rate of $0.49 \%$ [2]. Data on micronutrient status among children below 15 years is limited.

Zinc deficiency was most prevalent in this study. This is in corroboration with previous studies, where zinc deficiency in HIV-infected children was found to be $54.3 \%$ [13], $77.1 \%$ [14], and 60\% [15], respectively. Earlier reports show that zinc plays an important role in modulating the function of HIV viral enzymes mainly integrase and proteases [10, 11]. Hence, it can be proposed that advanced HIV infection is usually associated with chronic and recurrent infections, which predispose to zinc deficiency and vice versa.

When HIV-infected children on highly active antiretroviral therapy (HAART) and not on HAART were compared, various studies have demonstrated mean serum zinc levels to be higher, with decreased prevalence of zinc deficiency in HIV children on HAART therapy, both these aspects being statistically significant [13-15]. Similar results were seen among adult HIV-infected patients [24]. However, on the contrary, Jones et al. [25] and Wellinghausen et al. [26] documented that zinc deficiency remains highly prevalent in HIV-infected adults on HAART. Siberry et al. [27] and Mocchegiani et al. [28] in their studies have shown HAART reduces viral load, opportunistic infections, improves immune status, and general condition and thereby, decreases the number of HIV seropositive children with zinc deficiency. Thus, there are varying results with serum zinc levels in HIV-infected children on HAART.

Duration of treatment does not influence micronutrient levels as per Ndeezi et al. [13], implying that HAART may protect against zinc deficiency, but cannot completely eliminate it, indicating that supplementation of zinc would be essential once HIV is diagnosed. As per Ndeezi et al. [13], 
Table 2. Comparison of human immunodeficiency virus (HIV) immunological classification and HIV clinical staging with CD4 levels and serum micronutrient levels

\begin{tabular}{|c|c|c|c|c|c|}
\hline \multirow{2}{*}{ Variable } & \multicolumn{4}{|c|}{ Immunological classification } & \multirow{2}{*}{$p$} \\
\hline & None $(n=74)$ & Mild $(n=14)$ & Advanced $(n=7)$ & Severe $(n=5)$ & \\
\hline $\begin{array}{l}\text { CD4 levels; } \\
\text { median (IQR) }\end{array}$ & $855.50(1,158)$ & $405.50(108)$ & $314.00(59)$ & $47.00(80)$ & $0.000^{*}$ \\
\hline $\begin{array}{l}\text { Zinc levels; } \\
\text { median (IQR) }\end{array}$ & $57.06(395)$ & $64.82(134)$ & $44.70(243)$ & $18.25(37)$ & $0.043^{\star}$ \\
\hline $\begin{array}{l}\text { Copper levels; } \\
\text { median (IQR) }\end{array}$ & $181.45(648)$ & $180.70(203)$ & $150.30(350)$ & $126.30(183)$ & 0.555 \\
\hline $\begin{array}{l}\text { Iron levels; } \\
\text { median (IQR) }\end{array}$ & $170.60(514)$ & $212.70(386)$ & $201.50(311)$ & $126.20(142)$ & 0.125 \\
\hline \multirow{2}{*}{ Variable } & \multicolumn{4}{|c|}{ Clinical staging } & \\
\hline & Stage $1(n=54)$ & Stage $2(n=34)$ & Stage $3(n=12)$ & $p$ & \\
\hline $\begin{array}{l}\text { CD4 levels; } \\
\text { median (IQR) }\end{array}$ & $826.00(1,387)$ & $622.50(1,240)$ & $712.00(1,632)$ & $0.001^{*}$ & \\
\hline $\begin{array}{l}\text { Zinc levels; } \\
\text { median (IQR) }\end{array}$ & $53.74(243)$ & $53.63(395)$ & $53.15(395)$ & 0.836 & \\
\hline $\begin{array}{l}\text { Copper levels; } \\
\text { median (IQR) }\end{array}$ & $164.40(648)$ & $188.30(514)$ & $170.60(674)$ & 0.259 & \\
\hline $\begin{array}{l}\text { Iron levels; } \\
\text { median (IQR) }\end{array}$ & $167.80(438)$ & $211.95(475)$ & $174.80(535)$ & $0.000^{*}$ & \\
\hline
\end{tabular}

Table 3. Predictors of serum zinc in human immunodeficiency virus (HIV) infected subjects

\begin{tabular}{l|c|c|}
\hline \multirow{2}{*}{ Predictors } & \multicolumn{2}{|c|}{ Serum zinc $(n=62)$} \\
\cline { 2 - 3 } & Coefficient $(95 \% \mathrm{Cl})$ & $p$ value \\
\hline HIV clinical stages \\
\hline Stage 2 & $0.039(-10.61-14.09)$ & 0.779 \\
\hline Stage 3 & $0.328(-9.16-50.31)$ & 0.171 \\
\hline HIV immunological classification \\
\hline Mild & $0.132(-8.05-23.13)$ & 0.337 \\
\hline Advanced & $0.048(-20.13-27.54)$ & 0.757 \\
\hline \multicolumn{1}{|c|}{ Severe } & $-0.41(-67.6-4.46)$ & 0.085 \\
\hline Undernourished & $0.20(-3.82-23.19)$ & 0.157 \\
\hline $\begin{array}{l}\text { Not on antiretroviral } \\
\text { therapy }\end{array}$ & $0.143(-6.74-21.81)$ & 0.305 \\
\hline
\end{tabular}

Reference values*: clinical stage 1, none immunological classification, normal nutrition and on $A R T$

of the 44 children on HAART, 13 (29.5\%) had low serum zinc compared to 121 of $203(59.6 \%)$ in the non-HAART group. This difference was statistically significant (adjusted OR 3.7 [95\% CI: 1.8-7.7]). Contrastingly, in our study, of the 76 children on ART, 53 (68\%) had deficiency of zinc compared to 9 of $24(37.5 \%)$ children in the non-ART group; the difference was statistically significant with $p$ value of 0.017 between both the groups. Thus it probably implies that in our population,zinc supplementation should be initiated along with ART,since higher percentage of zinc deficiency was documented in HIV infected children who were on ART.
Contrary to other studies [13-15], majority of our study population were in clinical stage 1 and 2, with few (12/100) having stage 3 diseases. Normal immunity (74\%), advanced (7\%), and severe immunosuppression (5\%) was present in our study and was not concordant with previous studies [1315]. Prior studies $[14,15]$ have shown that, with a worsening status in the WHO clinical staging of HIV disease, there was reduction in mean serum zinc levels. Yarhere et al. [15] had found significant difference in mean serum zinc levels between subjects in stages 1 and 2, and those in stages 3 and 4 , with the latter having lower mean levels. However in this study, mean serum zinc levels in clinical stages did not show a marked difference, with stage 1 group having the lowest mean (65.86 [58.25 SD]). From the above it is clear that zinc deficiency was more in the early stages, and also in none and mild categories of immunosuppression suggesting that zinc levels can be low even during early stages of the disease. If the zinc levels in the same population group are studied over a period of time, it may give better concepts. By multiple linear regression analysis, zinc deficiency did not correlate with clinical stage, immunological classification, and nutritional status.

Zinc and copper are enzyme cofactors, with their plasma levels being regulated by metallothionein proteins. With this regulation, copper levels decreases as zinc levels increases and vice versa. Thus, copper supplementation should be done simultaneously with zinc supplementation. In our study, copper levels were high in $74 \%$ cases and copper deficiency was present in two children. This is similar to study on adult HIV patients by Graham et al. [29]. Copper deficiency of $25 \%$ was reported among HIV-infected children by Eley et al. [30]. 
Study by Swetha et al. [16] documented $51.4 \%$ of patients with deficiency in serum folate and iron levels, which were consistent with the low iron and folate dietary intakes. However in our study, iron deficiency was present in a single child; rest of the children had normal to high levels of serum iron, probably because of the diet they were on, the details of which were not assessed. Therefore, the reason for high serum iron levels could not be ascertained.

The limitations of this study were the relatively small sample size and lack of follow-up. A longitudinal study would be more accurate regarding study changes in micronutrient levels with disease progression and severity. Since the study questionnaire did not have specific questions related to the diet of the study participants, the authors cannot comment on the type of diet consumed by the study participants.

\section{Conclusions}

Our study showed that among micronutrients, zinc deficiency was common in children with HIV, did not correlate with clinical stage, immunological classification, nutritional status, and receipt of ART. We suggest, in this population, that zinc needs to be supplemented with ART, even during early stages of HIV diseases.

\section{Acknowledgements}

We thank the children involved in the research and KSAPS for granting us permission to conduct the study.

\section{Conflict of interest}

The authors declare no conflict of interest with respect to the research, authorship, and/or publication of this article.

\section{References}

1. HIV/AIDS in the context of other global challenges, Global 2015. Special report for the UN high level meeting on AIDS, 8-10 June 2011.

2. National Institute of Medial Statistics, ICMR \& NACO, DAC, Ministry of Health \& Family Welfare, Government of India, New Delhi 2012. National AIDS Control Organization. Technical report: India HIV estimates.

3. Sudharshan S, Biswas J. Introduction and immunopathogenesis of acquired immune deficiency syndrome. Indian J Ophthalmol 2008; 56: 357-362.

4. Calder PC, Kew S. The immune system: a target for functional foods? Br J Nutr 2002; 88 Suppl 2: S165-177.

5. Friis H. Micronutrient interventions and HIV infection: a review of current evidence. Trop Med Int Health 2006; 11: 1849-1857.

6. Fischer Walker C, Black RE. Zinc and the risk for infectious diseases. Annu Rev Nutr 2004; 24: 255-275.

7. Allard JP, Aghdassi E, Chau J, Salit I, Walmsley S. Oxidative stress and plasma antioxidant micronutrients in with HIV infection. Am J Clin Nutr 1998; 67: 143-147.

8. Bhaskaram P. Micronutrient malnutrition, infection, and immunity: an overview. Nutr Rev 2002; 60 (5 Pt 2): S40-45.

9. O’Dell BL. Role of zinc in plasma membrane function. J Nutr 2000; 130 (5 Suppl): 1432S-1436S.

10. Zhang ZY, Reardon IM, Hui JO, et al. Zinc inhibition of renin and the protease from human immunodeficiency virus type 1 . Biochemistry 1991, 30: 8717-8721.
11. Black RE. Zinc deficiency, infectious disease and mortality in the developing world. J Nutr 2003; 133 (5 Suppl 1): 1485S-1489S.

12. Kurtz J, Wegner KM, Kalbe M, et al. MHC genes and oxidative stress in sticklebacks: an immuno-ecological approach. Proc Biol Sci 2006; 273: 1407-1414.

13. Ndeezi G, Tumwine JK, Bolann BJ, Ndugwa CM, Tylleskar T. Zinc status in HIV infected Ugandan children aged 1-5 years: a cross sectional baseline survey. BMC Pediatr 2010; 10: 68 .

14. Anyabolu HC, Adejuyigbe EA, Adeodu OO. Serum micronutrient status of HAART-naïve, HIV infected children in South Western Nigeria: a case controlled study. AIDS Res Treat 2014; 2014 : 351043.

15. Yarhere IE, Ugwu RO, Eneh AU. Serum zinc levels in HIV infected children attending the University of Port Harcourt Teaching Hospital, Port Harcourt, Nigeria. Niger J Paed 2014; 41: 110-115.

16. Swetha GK, Hemalatha R, Prasad UV, Murali V, Damayanti K, Bhasker V. Health and nutritional status of HIV infected children in Hyderabad, India. Indian J Med Res 2015; 141: 46-54.

17. WHO Multicentre Growth Reference Study Group. WHO Child Growth Standards: Length/height-for-age, weight-for-age, weightfor-length, weight-for-height and body mass index-for-age: Methods and development. World Health Organization, Geneva 2006.

18. Indian Academy of Pediatrics Growth Charts Committee, Khadilkar V, Yadav S, Agrawal KK, et al. Revised IAP growth charts for height, weight and body mass index for 5 to 18 year old Indian children. Indian Pediatr 2015; 52: 47-55.

19. WHO case definitions of HIV for surveillance and revised clinical staging and immunological classification of HIV related disease in adults and children. WHO Press, Geneva 2007.

20. Wright M, Clifford W. Laboratory assessment of nutritional status. In: Duggan C, Watkins JB, Walker WA (eds.). Nutrition in Pediatrics: Basic Science, Clinical Applications. $4^{\text {th }}$ ed. B.C. Decker Inc, Hamilton 2008; 15-25.

21. Jiamton S, Pepin J, Suttent R, et al. A randomized trial of the impact of multiple micronutrient supplementation on mortality among HIV-infected individuals living in Bangkok. AIDS 2003; 17: 24612469.

22. van Lettow M, Harries AD, Kumwenda JJ, et al. Micronutrient malnutrition and wasting in adults with pulmonary tuberculosis with and without HIV co-infection in Malawi. BMC Infect Dis 2004; 4: 61.

23. Miller WC, Powers KA, Smith MK, Cohen MS. Community viral load as a measure for assessment of HIV treatment as prevention. Lancet Infect Dis 2013; 13: 459-464.

24. Rousseau MC, Molines C, Moreau J, Delmont J. Influence of highly active antiretroviral therapy on micronutrient profiles in HIV-infected patients. Ann Nutr Metab 2000; 44: 212-216.

25. Jones CY, Tang AM, Forrester JE, et al. Micronutrient levels and HIV disease status in HIV-infected patients on highly active antiretroviral therapy in the Nutrition for Healthy Living cohort. J Acquir Immune Defic Syndr 2006; 43: 475-482.

26. Wellinghausen N, Kern WV, Jochle W, Kern P. Zinc serum level in human immunodeficiency virus-infected patients in relation to immunological status. Biol Trace Elem Res 2000; 73: 139-149.

27. Siberry GK, Ruff AJ, Black R. Zinc and human immunodeficiency virus infection. Nutr Res 2002; 22: 527-538.

28. Mocchegiani E, Muzzioli M, Gaetti R, Veccia S, Viticchi C, Scalise G. Contribution of zinc to reduce CD4+ risk factor for 'severe' infection relapse in aging: parallelism with HIV. Int J Immunopharmacol 1999; 21: 271-281.

29. Graham NM, Sorensen D, Odaka N, et al. Relationship of serum copper and zinc levels to HIV seropositivity and progression to AIDS. J Acquir Immune Defic Syndr 1991; 4: 976-980.

30. Eley BS, Sive AA, Abelse L, Kossew G, Cooper M, Hussey GD. Growth and micronutrient disturbances in stable, HIV-infected children in Cape Town. Ann Trop Paediatr 2002; 22: 19-23. 